\title{
Enhancing Perceived Safety in Human-Robot Collaborative Construction Using Immersive Virtual Environments
}

\author{
Sangseok You \\ Department of Information Systems and Operations Management \\ HEC Paris \\ 1 rue de la Libération \\ 78351 Jouy en Josas France \\ you@hec.fr \\ Jeong-Hwan Kim \\ Department of Civil and Environmental Engineering \\ 2350 Hayward \\ Ann Arbor, MI 48109 USA \\ kimjeo@umich.edu \\ SangHyun Lee \\ Department of Civil and Environmental Engineering \\ 2350 Hayward \\ Ann Arbor, MI 48109 USA \\ shdpm@umich.edu \\ Vineet Kamat \\ Department of Civil and Environmental Engineering \\ 2350 Hayward \\ Ann Arbor, MI 48109 USA \\ vkamat@umich.edu \\ Lionel P. Robert Jr. \\ School of Information \\ University of Michigan \\ 105 S. State St. \\ Ann Arbor, MI 48105 USA \\ lprobert@umich.edu
}

\section{Forthcoming in: Automation in Construction}




\title{
Enhancing Perceived Safety in Human-Robot Collaborative Construction Using Immersive Virtual Environments
}

\begin{abstract}
Advances in robotics now permit humans to work collaboratively with robots. However, humans often feel unsafe working alongside robots. Our knowledge of how to help humans overcome this issue is limited by two challenges. One, it is difficult, expensive and time-consuming to prototype robots and set up various work situations needed to conduct studies in this area. Two, we lack strong theoretical models to predict and explain perceived safety and its influence on human-robot work collaboration (HRWC). To address these issues, we introduce the Robot Acceptance Safety Model (RASM) and employ immersive virtual environments (IVEs) to examine perceived safety of working on tasks alongside a robot. Results from a between-subjects experiment done in an IVE show that separation of work areas between robots and humans increases perceived safety by promoting team identification and trust in the robot. In addition, the more participants felt it was safe to work with the robot, the more willing they were to work alongside the robot in the future.

Keywords: Human-Robot Work Collaboration (HRWC); Immersive Virtual Environment (IVE); Robot Acceptance Safety Model (RASM); Masonry; Safety; Trust; Team Identification; Intention to Work with Robot.
\end{abstract}




\section{Enhancing Perceived Safety in Human-Robot Collaborative Construction Using Immersive Virtual Environments}

\section{Introduction}

Human-robot work collaboration (HRWC) can be used to describe work situations

where humans and robots work side by side to complete a task. Advances in robotics now permit humans to work collaboratively with robots (Bauer, Wollherr, \& Buss, 2008; You \& Robert, 2017). This collaboration allows humans to off-load repetitive and tedious tasks to their robots (Sauppé \& Mutlu, 2014; Sirkin, Zinser, \& Rose, 2015). This is particularly beneficial because such tasks are often responsible for a class of physical injuries labeled as repetitive motion injuries (Schneider \& Susi, 1994). The use of robots also frees up humans to focus on other tasks that cannot be easily performed by robots (You, Ye, \& Robert, 2017).

HRWC may be particularly important for construction work because many construction tasks require repetitive physical movements and the need for collaborative work.

One major challenge to leveraging HRWC is that humans often feel unsafe working around robots (Bartneck, Kulić, Croft, \& Zoghbi, 2009; Tan, Duan, Zhang, Kato, \& Arai, 2009). Humans are less willing to work with or alongside robots when they believe it is unsafe to do so, regardless of the actual level of safety (Atkinson \& Clark, 2014). Perceived safety is the degree to which someone believes it is safe to engage in a behavior. Despite this, the existing literature on safety and robots has focused only on technical design issues (Park, Kim, Song, \& Kim, 2007; Vermeulen \& Wisse, 2010) and has ignored the issues associated 
1 with perceived safety. Yet, our human behavior is often driven by how we perceive the world. Despite the importance of perceived safety in facilitating HRWC, two challenges have

limited our ability to advance our understanding of this area in the context of construction

work. One, it is difficult, expensive and time-consuming to prototype robots and set up

various work situations needed to conduct studies in this area. For example, one could easily

imagine the need to vary the design of the robot, the task and the characteristics of the

construction sites. We believe that the use of immersive virtual environments (IVEs) can help

to overcome these issues. Immersive virtual environments (IVEs) are computer-generated

simulated environments that represent a physical environment and allow user interactions

with virtually rendered objects (Heydarian et al., 2015; Kamat \& Martinez, 2005). By

adapting IVEs, various types of robots, interactions, and tasks can be easily tested and

evaluated to determine the best HRWC practices, without the need to build and evaluate

physical prototypes (Garg \& Kamat, 2013; Messner, 2006; Whisker et al., 2003).

Two, we lack strong theoretical models that can predict and explain perceived safety

and its influence on HRWC. We believe such theoretical models should be more specific with

regard to perceived safety rather than more general with regard for any outcome related to

work or collaboration. To address this challenge, we introduce the Robot Acceptance Safety

Model (RASM). The RASM asserts that individuals' willingness to work with a robot is

relative to their perceived safety associated with the task involving the robot. 
human and robot. RASM asserts that: (1) Separation of the work area between a human and a

robot increases one's willingness to work with that robot by facilitating perceived safety; (2)

The separation of the work area increases perceived safety by promoting team identification and trust in the robot; and (3) The more individuals believe it is safe to work alongside a robot the more likely they will be to work alongside the robot in the future.

To empirically test our model, we conducted an experimental study involving 30

participants. In this study, we employed IVEs in a simulation and experiment environment.

We used IVEs to create two conditions of a construction task involving a robot. In one condition, participants and their robot worked side by side but each had their own work area separated by a safety fence. In the other condition, participants and their robot worked in the same work area. We found that humans felt safer working with their robot when they each had their own work area separated by the fence. Separate work areas led to higher perceptions of safety by promoting team identification with and trust in the robot. Perceived safety promoted participants' willingness to work with their robot in the future. Results of this study contribute to our understanding of how to effectively employ robots at construction sites. The following sections of this paper describe the objectives, motivation, and current status of the use of IVEs in HWRC in the area of construction. Then we present the methodology of the research, followed by the study results. Finally, we discuss a summary of 
1 the contributions and future research implications.

\section{2. HRWC and Immersive Virtual Environments}

Research that falls under the heading of HRWC has been conducted for more than a decade (Arai, Takubo, Hayashibara, \& Tanie, 2000; Goodrich \& Schultz, 2007; Ikeura \& Inooka, 1995; Murphy, 2004; Reed \& Peshkin, 2008). Most of this research has focused on building safer robots. Scholars have developed technologies such as advanced controls (Ikeura \& Inooka, 1995; K. Kosuge, Yoshida, \& Fukuda, 1993; Kazuhiro Kosuge \& Kazamura, 1997; Vukobratović \& Ekalo, 1996), sensor equipment (Du \& Zhang, 2014; Vick, Surdilovic, \& Kruger, 2013; Vogel, Walter, \& Elkmann, 2013), and path-planning techniques (Thomessen, Hashimoto, Osumi, Niitsuma, \& others, 2014).

Advances in robotics now allow robots to work collaboratively alongside human workers in an interactive, intuitive, and safe manner (Kulić \& Croft, 2006; You \& Robert, 2017). In the past, safety fencing has been used to separate humans from robots to help to prevent injuries caused by physical contact (Vasic \& Billard, 2013). However, in cellular manufacturing environments, heavy-duty industrial robots are beginning to work in closer range with humans (Buchner, Wurhofer, Weiss, \& Tscheligi, 2013). An example of this is in BMW factories, in which robots work alongside human workers for automobile door assembly tasks (Knight, 2014). Although manufacturing is beginning to engage in more HRWC without safety fencing, this has not necessarily spilled over into construction work 
1 (Tan et al., 2009).

2 Construction sites present their own challenges that limit the ability to adopt the

3

4 are often more dynamic, unstructured, and physically demanding than others (Feng, Xiao, systems and practices developed for manufacturing environments. Construction environments are often more dynamic, unstructured, and physically demanding than others (Feng, Xiao, Willette, McGee, \& Kamat, 2015). The location of workspaces on a construction site is fluid

6 and temporary rather than fixed and permanent like in many manufacturing plants.

$7 \quad$ Workspaces on a construction site are also shared and more open than those at a manufacturing plant, making it more difficult to close off from other workers (Törner \&

Pousette, 2009). For this reason, a safety fence is often installed between a robot and a worker to avoid potential injuries. However, this can be cumbersome and problematic in construction work, where more interactive coordination between humans and robots may be beneficial (Lee, Lee, Lee, Kim, \& Han, 2007). In addition, there is no empirical evidence on whether such separation is necessary or beneficial for HRWC in construction work (B. Hayes \& Scassellati, 2013).

Despite the potential importance and relevance of perceived safety, it has received very little attention in the context of construction environments. We found no prior research that empirically examined perceived safety in the context of construction work with robots.

Researchers from other fields examining the impact of perceived safety have not focused on the work arrangement itself. Instead, this work is focused on the relationship between 
1 perceived safety and the characteristics of the robot, including motion and speed (Kulić \&

2 Croft, 2006; Or, Duffy, \& Cheung, 2009), behaviors such as presence of pre-warning of physical contact (Chen, King, Thomaz, \& Kemp, 2011), and design (Salvini, Laschi, \& Dario, 2010). Considering the increases in the adoption of robots in construction work and the distinct characteristics of these sites, there is an urgent need to examine perceived safety in HRWC in the context of construction work.

To address this, we employed an IVE to avoid time-consuming and costly prototype building while still effectively evaluating perceived safety of the task (Weistroffer, Paljic, Callebert, \& Fuchs, 2013). IVEs are proven to increase both experimental control and mundane realism, which enhances participants' engagement, thereby increasing experimental validity (Blascovich et al., 2002). For example, Heydarian et al. (2015) employed an IVE to measure the sense of presence felt by participants performing office-related activities. Weistroffer et al. (2013) used a virtual environment to evaluate the end-user's perception of a robot and its movement. Inoue et al. (2005) used virtual robots to test the effect of their movement. However, very little attention has been directed at the use of IVEs in HRWC or use of IVEs to study unstructured work environments such as construction sites. Therefore, our goal is to extend the current literature by implementing an IVE to understand how perceived safety influences HRWC in two unstructured work environments: (1) working with a robot in two work areas separated by a fence and (2) working with a robot within the same 
1 work area.

\section{3. Research Model and Hypotheses}

Safety is an important issue in construction work because accidents can lead to serious injuries and even fatalities (Törner \& Pousette, 2009; Zou \& Zhang, 2009). Heavy-duty machinery is one of the primary causes of accidents on construction sites (Sawacha, Naoum, \& Fong, 1999), and the fear of being hit by such equipment is a major reason many construction workers feel unsafe (Larsson \& Field, 2002). In addition, safety concerns in the form of fear and worry have been found to increase cognitive load for workers, often contributing significantly to worker burnout (Nahrgang, Morgeson, \& Hofmann, 2011). To examine HRWC for construction tasks, we propose the Robot Acceptance Safety Model (RASM). RASM consists of several important factors influencing perceived safety in HWRC. In general, the RASM proposes that collaborative attitudes and beliefs regarding the robot can impact the perceived safety associated with the collaborative task. In this study, the RASM specifically asserts that the separation of work areas between workers and their robot increases the individuals' perceived safety, and that the impact of work separation on perceived safety is mediated by team identification and trust in robots. RASM also posits that increases in perceived safety increase an individual's willingness to work with the robot in the future. The RASM model is depicted in Figure 1. 


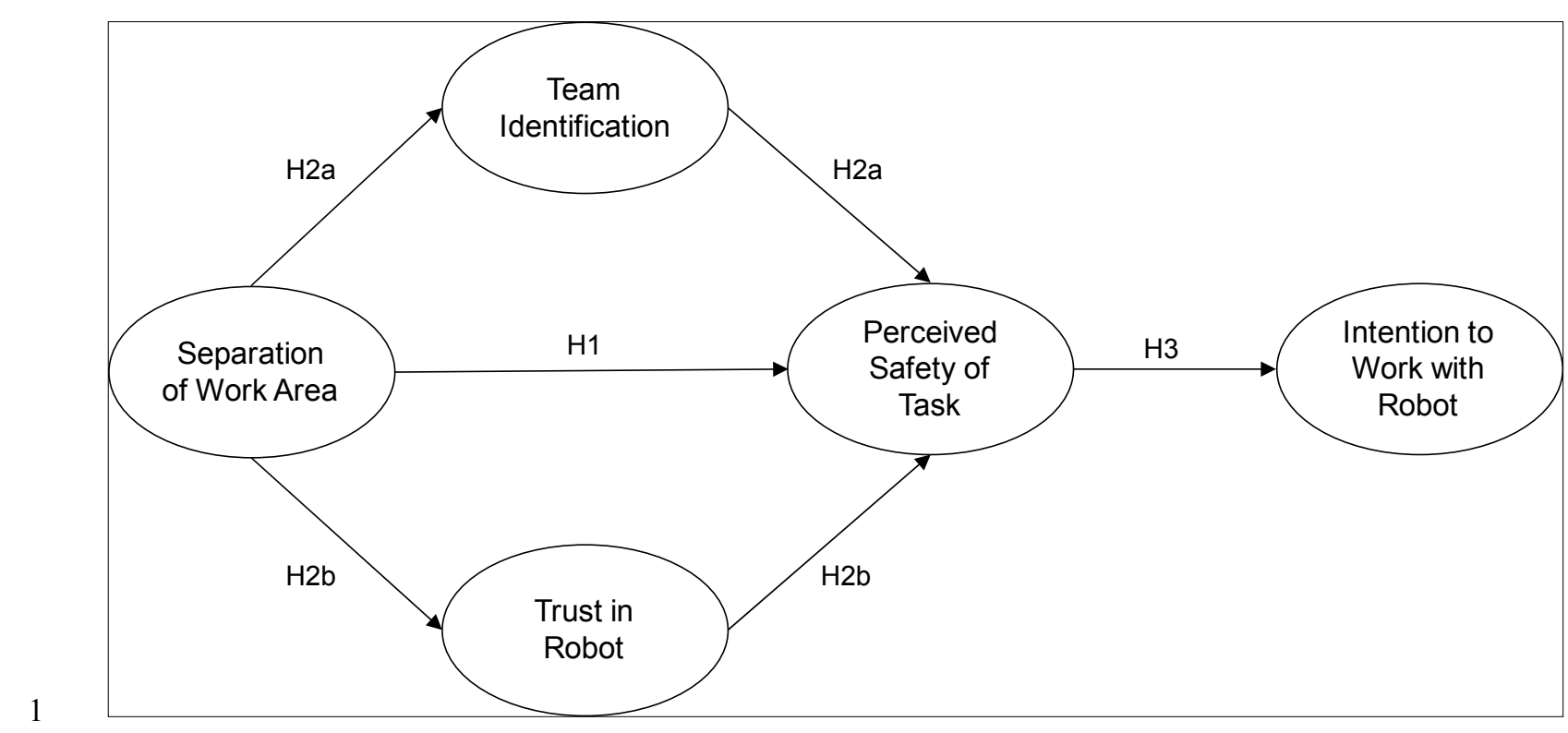

Figure 1 RASM Model

3

4

5

6

7

\subsection{Hypotheses}

The greater the separation is between humans and robots, the higher the degree of

perceived safety. This assertion is supported by early research on personal space, a concept

originally introduced by Hall (1966). A common definition of personal space is "an area with

an invisible boundary surrounding a person's body, into which intruders may not come"

(Sommer, 1969, p. 26). Personal space is important to humans because it allows us to regulate

the degree of access others have to us (Strube \& Werner, 1984). The ability to control the

degree of access to ourselves is directly related to our emotional well-being (Dosey \&

Meisels, 1969; Kennedy, Gläscher, Tyszka, \& Adolphs, 2009). When someone violates our

personal space by moving too close to us we can feel uncomfortable and at times threatened

by their presence (Dosey \& Meisels, 1969; Kennedy et al., 2009; Walters et al., 2005). 
1 closeness between two actors in understanding the degree of personal space needed (Dosey \&

2 Meisels, 1969; Hall, 1966). We need less personal space when interacting with those we are

emotionally close to on a personal level (Burgoon, 1978). For example, people would need

much less personal space when interacting with their spouse than with a stranger (Hall, 1966).

Individuals tend to require more personal space when interacting with others they believe are

a threat. According to Dosey and Meisels (1969), when we believe others are a threat,

increasing our personal space or separation from them helps to increase our feelings of safety.

More recent research on personal space has dug deeper into understanding the mechanism

behind it by examining facial and brain activities (Kennedy et al., 2009; Lieberz et al., 2017).

Based on the research on personal space, we believe separating the work area with a

safety fence will lead to more rather than less perceived safety, for several reasons. First, the

degree of personal space is dependent on someone's relationship with the other actor (Hall,

1966; Sommer, 1969). Although it is possible for humans to develop a strong personal

relationship with robots (Robert \& You, 2015), we believe this is unlikely to happen in the

context of construction work. As we stated earlier, the fear of being hit by construction

equipment is a major reason many humans feel unsafe around construction sites (Larsson \&

Field, 2002). This means that humans are more likely to view a robot on a construction site as a threat rather than a close personal friend (Mumm \& Mutlu, 2011; Takayama \& Pantofaru, 2009). The more humans view something as a threat, the more personal space or separation 
1 they prefer to have from it (Dosey \& Meisels, 1969). have over the interaction between themselves and the other actor. In general, the more control

4 someone has over the interaction with another actor, the less threatened that person is by that actor (Strube \& Werner, 1984). The safety fence should increase the degree of control

6 individuals feel they have over their interaction with the robot. Therefore, the inclusion of the safety fence itself is also likely to increase perceived safety. In sum, an individual is likely to

8 have higher levels of perceived safety when separated from the robot by a safety fence, which 9 leads to our first hypothesis: identification and trust in the robot. Team identification is the degree to which an individual feels a connection or strong bond with other members of their team (Robert, 2013; Robert, Dennis, \& Ahuja, 2008; You \& Robert, 2018). Trust in a robot can be described as the degree to which an individual believes the robot is capable, credible, and reliable (Jian, Bisantz, \& Drury, 2000; Yagoda \& Gillan, 2012). Both should help explain the impact of separate work areas on perceived safety. 
1 and the robot to promote team identification and trust in the robot. Individuals are less likely

2 to bond with or trust a robot when they are constantly fearful and worried about its presence

3 (Groom et al., 2011; Ximenes, Moreira, \& Kelner, 2014). Fear and worry regarding someone

4 or something can block the formation of a common identity and trust between two actors

5 (Williams, 2007). Providing the personal space needed between the individual and robot

6 should decrease fear and worry (Sardar, Joosse, Weiss, \& Evers, 2012; Takayama \&

7 Pantofaru, 2009). When fear and worry are removed, it becomes possible to form a common

8 identity and to develop trust in the robot. Research has shown that working alongside a robot

9 toward a common goal can promote the development of the strong emotional bonds needed to

10 facilitate team identification and trust (Groom \& Nass, 2007).

After team identification and trust are developed, individuals should feel safer

working alongside the robot. Team identification and trust have been associated with feelings

of safety (Tharaldsen, Mearns, \& Knudsen, 2010; Törner \& Pousette, 2009). Individuals feel

safer working with others they share a common identity with and trust (Tharaldsen et al.,

2010; Williams, 2007). Hence the impact of separating the work areas on perceived safety

should occur by increasing team identification and trust in the robot. Therefore, we

hypothesize the following:

H2: (a) Team identification and (b) trust in robots mediate the positive impact of 
promote the worker's intention to work with the robot in the future. We examined intention to

work with the robot in this study because behavioral intention is considered to be the

immediate predictor of actual behavior (Ajzen, 1991).

Perceived safety should increase an individual's willingness to work with the robot in the future. Theories on human behavior state that future behavior is the result of attitudes and beliefs associated with that behavior (Ajzen, 1991; Fishbein, 1979). Research has shown that the more positive someone's attitude or beliefs are regarding a behavior, the more likely that person is to perform that behavior in the future (Ajzen, 1985; Liker \& Sindi, 1997). This has been shown to be particularly true when it comes to predicting future interactions with technology (Robert \& Sykes, 2016). Similarly, we assert that the more someone believes performing a task alongside a robot is safe, the more likely that person is to want to work alongside that robot again. Therefore, individuals who worked in separate work areas from their robot should be more willing to work alongside the robot in future because they believe it is safe to do so. This leads to the third hypothesis:

H3: Perceived safety of the task increases intention to work with the robot in the future.

\section{Experiment in an Immersive Virtual Environment}

To test our hypotheses, we conducted a between-subjects experiment (shared work 
1 area vs. separate work areas) in a controlled lab environment. We employed an IVE to

2 examine individuals' perceptions of their interaction with a robot on a construction site. The participants performed a human-robot collaborative masonry task during the experiment. The

$4 \quad$ virtual environment simulated a realistic masonry task in which an individual performs a task

5 alongside a robot. The masonry task was selected for several reasons. One, it has all the

6 characteristics of the type of tasks a robot would be most useful for: it is physically

7 demanding and labor-intensive and requires repetition. Two, construction robots that directly

8 support masonry work are already commercially available (e.g., SAM100 developed by

9 Construction Robotics $\left.{ }^{1}\right)$.

10

\subsection{Participants}

Our experiment involved 30 participants recruited at a large national university in the United States. The mean $(\mathrm{M})$ age was 25.4 years (standard deviation $[\mathrm{SD}]=4.48$ years); 11 (37\%) were female. Each participant was randomly assigned to one of two conditions:

separate work areas or a shared work area. There were 16 participants in the separate work areas condition and 14 in the shared work area condition.

\subsection{Design of Immersive Virtual Environments (IVEs)}

We created an IVE using Unity $3 \mathrm{D}^{2}$ game engine. The software provided a wide array of interactive components (e.g., position and orientation, camera, light, renderer) for

\footnotetext{
${ }^{1} \mathrm{http}: / / \mathrm{www}$. construction-robotics.com

2 http://www.unity3d.com
} 
1 building the experimental setting in a virtual space. In addition, we employed Oculus Rift Dev

2 Kit $2^{3}$ Head-mounted Display (HMD) to generate an IVE during the experiment. As shown in

3 Figure 2, Unity 3D creates an illusion of depth to a stereoscopic view by rendering two

4 slightly different images that are shifted horizontally. The rendered images are sent to a

5 computer that is equipped with motion sensors detecting relative positions and movements of

6 the HMD. This combination of devices allows for the orientation of the participant's position

7 in a virtual space. For instance, if a participant moves toward the left and rotates his or her

8 head to the left while wearing the HMD, the avatar in the virtual environment also moves to

9 the left and the field of view also moves according to the body movement. Oculus Rift Dev

10 Kit 2 is capable of capturing and tracking positions up to 2-3 meters. grab, hold, and release blocks using a Nintendo Wii MotionPlus controller. We employed the motion controller because it requires only one hand to hold and press buttons, which matched our experimental task. To reduce clutter and enhance the ease of interaction, we connected the controller to the computer via Bluetooth. We limited the objects that could be picked up by the virtual hand to blocks to simpify the interaction.

\footnotetext{
${ }^{3}$ https://www.oculus.com/en-us/dk2/
} 


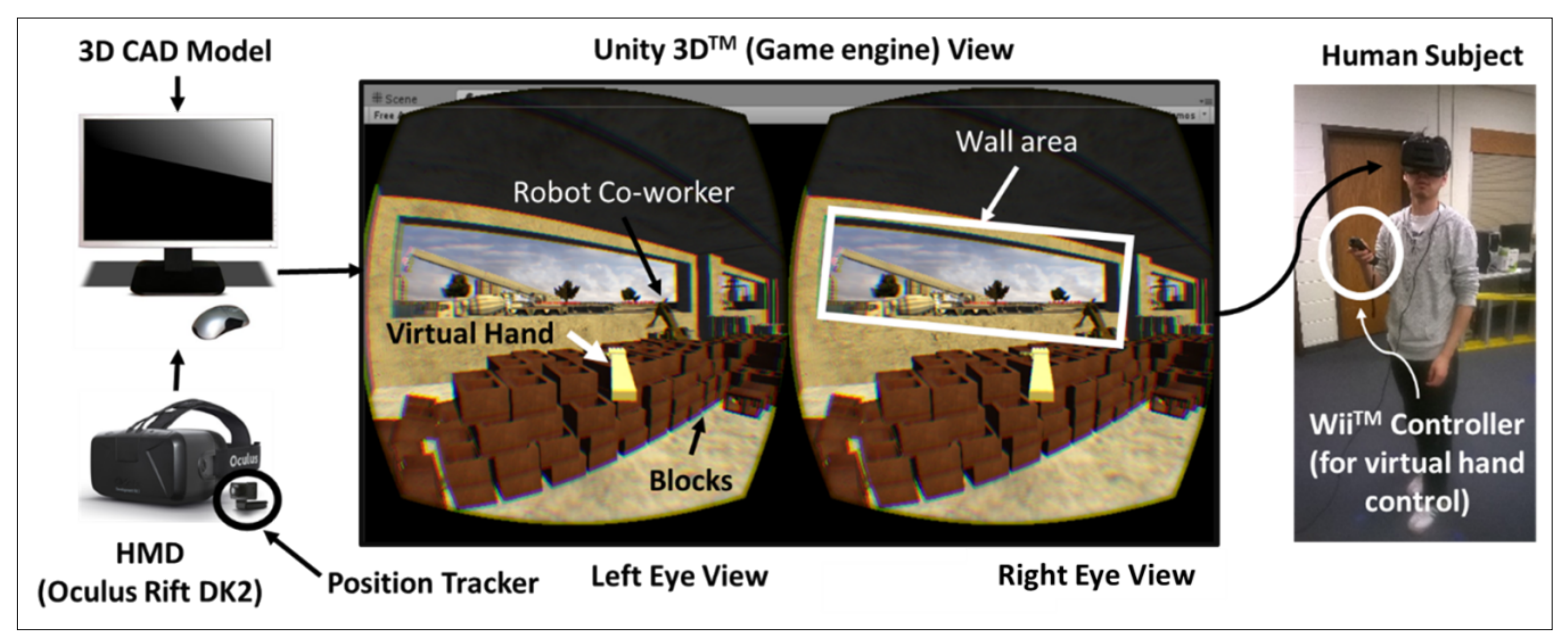

Figure 2 General Settings of Immersive Virtual Environment of Masonry Work

The experiment consisted of two conditions: working in separate work areas vs.

working in a shared area with the robot. Figure 3 illustrates the experimental manipulation. In

the separate work area condition, participants and the robot were separated by a partition

consisting of a pile of blocks in the middle of the work area. In the shared work area

condition, participants and the robot worked without a partition between them. Using two

questions, including “My work area was separate from robot's work area," based on 5-point

Likert scale, we asked participants whether the manipulation was successful at creating the perception of separation. We found a significant difference between the separate work area condition $(\mathrm{M}=2.90, \mathrm{SD}=0.69)$ and the shared work area condition $(\mathrm{M}=2.17, \mathrm{SD}=0.98$,

$$
\mathrm{t}(27)=2.18, p<0.05)
$$



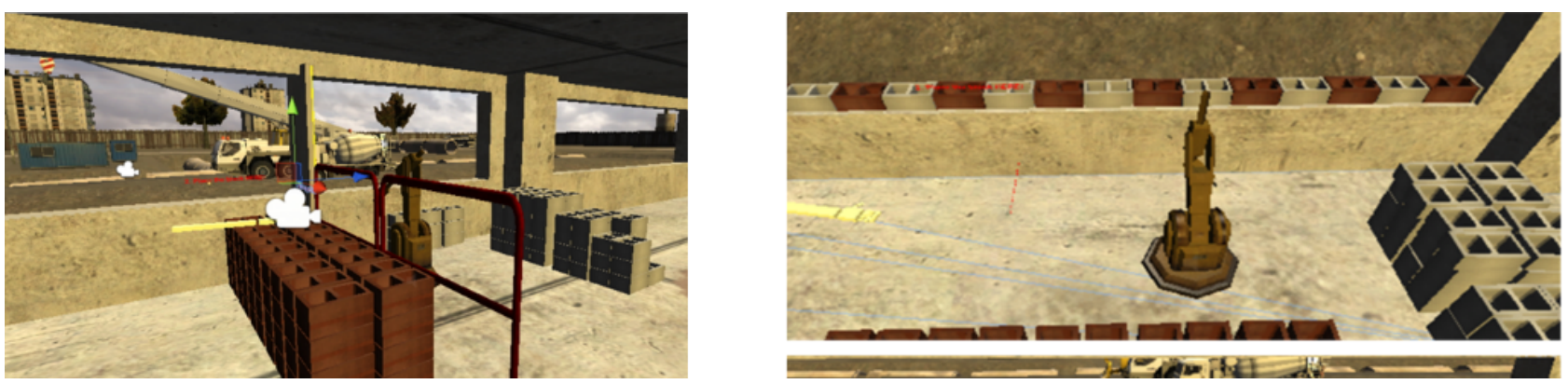

Figure 3 Experimental Setting

\subsection{The Masonry Task}

Our experiment simulated a simple masonry task in an IVE. The objective of the task

was to repeat the action of grabbing a concrete block and placing it on a designated area of a

virtual wall that was under construction. In this setting, participants were to build the virtual

wall with a robotic collaborator by controlling a virtual hand using a remote controller.

Figure 4 illustrates the virtual masonry task from participants' viewpoint using the

HMD. By maneuvering a virtual hand, shown in yellow in the red circle in the image,

participants grabbed one block from the pile and dropped it onto the wall. Once the block was

moved close to the bottom of the wall, shown in (a) in Figure 4, it was automatically snapped

into position next to the previously placed block, shown in (b) in Figure 4 . This allowed the

participants to perform the task without putting extra effort for precise alignment of the

blocks. During the task, the robot was consistently visible to the participant in both

conditions. The robot was programmed to place blocks automatically every 7 seconds, which

was roughly the same speed of human participants.

The masonry task required a limited range of maneuvering to move the blocks. That 
1 is, the task did not involve actions such as applying mortar between blocks. The simplification

2 of the masonry task allowed two things. First, it could be easily performable by almost all

3 participants recruited from a university student population. Second, reducing the complexity

4 of the actions made the robot's actions more visible to participants, which increased their

5 awareness of the robot's operations in the construction environment.

\subsection{Experimental Procedure}

The experiment took place in a large room designated for studies using IVE. This was

to ensure the participants' safety during the use of the HMD, which does not allow visibility

outside the display and thus requires the use of an open area. There were two in the room: one computer kiosk was used for the experimental stimulus and the other, located on the other side of the room, was used for completing questionnaires. This study was approved by the Institutional Review Board (IRB) of the authors' institution. 
The experiment was composed of three main parts: pre-questionnaire, interaction with

the robot in the IVE, and post-questionnaire. Upon arrival, participants were greeted and given a description of the study along with a written consent form. After consenting to participate, they were guided to a laptop computer to fill out a short pre-questionnaire, which asked demographic information such as gender, age, and previous videogame experience. Then participants received written instructions with images. The instructions contained detailed information regarding the experimental task, use of the HMD, and interaction using Nintendo Wii controller in the IVE. In order to ensure their clear understanding of the task in the IVE, we asked participants whether they had any questions regarding the experiment before they proceeded to the next step of the experiment. Participants were then guided to the computer kiosk to use the IVE. All participants went through a calibration of the HMD and 2-minute training of performing the experimental task. Participants who reported any physical or mental discomfort during this calibration and training were dismissed immediately.

Next, participants completed the study in the condition they were randomly assigned to: working in the same area with the robot or a separate area from the robot. They were asked to perform a masonry task that involved picking up concrete blocks and placing them in a designated area to complete a wall. Duration of the interaction was 7 minutes. After participants finished the experimental task in the IVE, we guided them back to the laptop 
1 computer to fill out the post-questionnaire. The post-questionnaire contained measures such

2 as perceived safety, trust, team identification, and intention to work with the robot. After

3 finishing, they were debriefed, paid, and dismissed.

4

5

\subsection{Measures}

\subsubsection{Team identification}

Team Identification was measured to capture the degree to which individuals

identified themselves with their human-robot team. An index of five items was adapted from

Brown et al. (1986) and measured team identification based on 5-point Likert scale (1 for "strongly disagree" to 5 for "strongly agree"). Example items include "I was happy with being identified as a member of this team." The construct was reliable (Cronbach's $\alpha=0.92$ ).

\subsubsection{Trust in robot}

Trust in the robot captured the extent to which individuals believed that the robot was trustworthy. The construct was measured using an index of four items adapted from Jian et al. (2000) based on a 5-point Likert scale (1 for "strongly disagree" to 5 for "strongly agree"). An example item included "The robot had integrity." The construct was reliable (Cronbach's $\alpha=0.88)$

\subsubsection{Perceived task safety}

Participants were asked to rate the degree to which they felt physical danger in the work area when performing the task alongside the robot. The construct consisted of three 
1 items adapted from Jermier, Gaines, and McIntosh (1989) and was measured using a 5-point

2 Likert scale (1 for "strongly disagree" to 5 for "strongly agree"). The original items captured the perceived danger in the environment and were reverse-coded to capture safety. An example item was "I was directly exposed to physical harm in carrying out the task." The construct was reliable (Cronbach's $\alpha=0.959)$.

\subsubsection{Intention to work with robot}

Finally, individuals were asked to rate the degree to which they would be willing to work with the robot in the future. An index of two items, including "I can see myself working with the robot in the future," was adapted from Venkatesh, Morris, Davis, and Davis (2003) and measured the construct based on a 5-point Likert scale (1 for "strongly disagree" to 5 for “strongly agree"). The construct was reliable (Cronbach's $\alpha=0.78)$.

\section{Analysis and Results}

We employed a partial least squares (PLS) approach to analyze the data. PLS is a component-based structural equation modeling technique in which measurement paths and structural paths among variables are modeled simultaneously (Chin, 1998). We employed PLS for several reasons. First, PLS allows us to test a structural model that includes latent variables. PLS has been widely adopted in various fields ranging from information systems to psychology for theory testing (Marcoulides \& Saunders, 2006). Second, PLS allows for the examination of causal relationships (Chin, 1998). Third, PLS requires a much smaller sample 
1 size than other latent modeling techniques. The general rule of thumb for a sample is 10 times

2 the number of paths leading to the most complicated variable (i.e. perceived safety with three

3 paths in our model; (Hair, Ringle, \& Sarstedt, 2011; Ringle, Wende, \& Will, 2005)). experience. None of the control variables yielded a statistically significant effect, so they were

6 excluded in the final model.

7

\subsection{Measurement Validity}

PLS produces both the measurement and the structural model. The variable measuring work area sharing was binary, 0 or 1 . All other variables in the model, including trust in the robot, team identification, perceived safety of the task, and intention to work with the robot, were reflective constructs.

In order to ensure discriminant validity among the variables, we reported factor loadings of all latent variables (Table 1). All items except one loaded at least 0.7 or greater to each of their constructs. The exception was the first item, trust in the robot, but we decided to keep this item in the analysis because it has good face validity. Overall, the results of factor analysis indicate discriminant and convergent validity (Fornell \& Larcker, 1981). 


\begin{tabular}{|c|c|c|c|c|c|c|}
\hline & \multirow{2}{*}{ Item } & \multicolumn{5}{|c|}{ Component } \\
\hline & & 1 & 2 & 3 & 4 & 5 \\
\hline \multirow{5}{*}{1} & Team Identification 1 & 0.73 & 0.26 & 0.45 & 0.13 & 0.06 \\
\hline & Team Identification 2 & 0.80 & 0.32 & -0.02 & -0.11 & 0.03 \\
\hline & Team Identification 3 & 0.78 & 0.29 & 0.37 & 0.25 & 0.08 \\
\hline & Team Identification 4 & 0.81 & -0.02 & 0.30 & 0.29 & 0.02 \\
\hline & Team Identification 5 & 0.87 & -0.13 & 0.20 & 0.19 & 0.20 \\
\hline \multirow{4}{*}{2} & Trust in Robot 1 & 0.18 & 0.64 & 0.29 & 0.15 & -0.10 \\
\hline & Trust in Robot 2 & 0.01 & 0.74 & 0.26 & 0.34 & 0.32 \\
\hline & Trust in Robot 3 & 0.19 & 0.90 & 0.19 & 0.10 & -0.14 \\
\hline & Trust in Robot 4 & 0.09 & 0.81 & 0.40 & -0.01 & -0.08 \\
\hline \multirow{3}{*}{3} & Perceived Safety of Task 1 & 0.35 & 0.33 & 0.78 & 0.17 & 0.10 \\
\hline & Perceived Safety of Task 2 & 0.27 & 0.31 & 0.87 & 0.14 & 0.07 \\
\hline & Perceived Safety of Task 3 & 0.29 & 0.39 & 0.82 & 0.14 & 0.00 \\
\hline \multirow{2}{*}{4} & Intention to Work with Robot 1 & 0.16 & 0.05 & 0.17 & 0.83 & 0.07 \\
\hline & Intention to Work with Robot 2 & 0.19 & 0.25 & 0.08 & 0.87 & 0.01 \\
\hline \multirow{2}{*}{5} & Previous Videogame Experience 1 & 0.05 & -0.47 & 0.23 & 0.29 & 0.70 \\
\hline & Previous Videogame Experience 2 & 0.17 & 0.07 & -0.03 & -0.05 & 0.93 \\
\hline
\end{tabular}

In addition to the factor analysis, we tested correlations among variables in the empirical model to ensure discriminant and convergent validity. Table 2 demonstrates descriptive statistics, the average variance extracted (AVE), correlations among variables, the square root of AVE, and internal composite reliability (ICR). The AVE represents the variance explained by the variable compared to the variance explained by the measurement error. As recommended by Fornell and Larcker (1981), values of the AVE of all latent variables are greater than 0.5 , which indicates convergence of the variables. Further, correlations among variables are below the square root of the AVE of each variable, which indicates discriminant validity among variables in the model. Last, all variables demonstrate 
2 Table 2 Descriptive Statistics, Average Variance Extracted (AVE), Correlations, and 3 Internal Composite Reliability (ICR)

\begin{tabular}{|l|l|c|c|c|c|c|c|c|c|c|c|}
\hline \multicolumn{1}{|c|}{ Variable } & Mean & SD & AVE & $\mathbf{1}$ & $\mathbf{2}$ & $\mathbf{3}$ & $\mathbf{4}$ & $\mathbf{5}$ & $\mathbf{6}$ & $\mathbf{7}$ \\
\hline $\mathbf{1}$ & Age & 25.40 & 4.48 & NA & NA & & & & & & \\
\hline $\mathbf{2}$ & $\begin{array}{l}\text { Previous Videogame } \\
\text { Experience }\end{array}$ & 2.33 & 0.89 & 0.73 & -0.27 & $0.86(0.84)$ & & & & & \\
\hline $\mathbf{3}$ & Work Area Sharing & 0.47 & 0.51 & NA & 0.23 & -0.01 & NA & & & & \\
\hline $\mathbf{4}$ & Team Identification & 3.54 & 0.80 & 0.76 & -0.09 & 0.21 & $.395^{*}$ & $0.87(0.94)$ & & & \\
\hline $\mathbf{5}$ & Trust in Robot & 3.75 & 0.80 & 0.74 & -0.15 & -0.12 & 0.32 & $.432^{*}$ & $0.86(0.92)$ & & \\
\hline $\mathbf{6}$ & $\begin{array}{l}\text { Perceived Safety of } \\
\text { Task }\end{array}$ & 3.98 & 1.15 & 0.93 & -0.06 & 0.13 & $.391^{*}$ & $.624^{* *}$ & $.650^{*}$ & $0.96(0.97)$ & \\
\hline $\mathbf{7}$ & $\begin{array}{l}\text { Intention to Work with } \\
\text { Robot }\end{array}$ & 3.50 & 0.80 & 0.82 & -0.08 & 0.18 & 0.30 & $.416^{*}$ & $.376^{*}$ & $.405^{*}$ & $0.91(0.90)$ \\
\hline
\end{tabular}

Note: $N=30$; Values on the diagonals are the square root of the AVE for each variable. Values in parentheses on the diagonals indicate internal composite reliability (ICR) of each variable. Work Area Sharing was coded using 0 and $1\left(0=\right.$ control condition, $1=$ treatment condition). ${ }^{*} . p<0.05 .{ }^{* *} . p<0.01$.

\subsection{Hypotheses Testing}

For testing the hypotheses, we assessed the significance of path coefficients in the structural model using SmartPLS 3.2 for the partial least squares. Examining the coefficients involved the standard bootstrapping method with 1,000 subsamples. To determine multicollinearity (i.e. two or more variables in the model are highly correlated) — which could undermine our analysis — we checked the variance inflation factors (VIF). VIF scores of 10 or higher are commonly used as an indication of problems with multicollinearity. The highest VIF value in our analysis was 1.60 , indicating little or no multicollinearity. Figure 5 shows the results our analysis placed within the research model. The standardized path coefficients $(\beta)$ are placed next to their corresponding paths and the variance explained $\left(\mathrm{R}^{2}\right)$ is placed above its corresponding variable. 


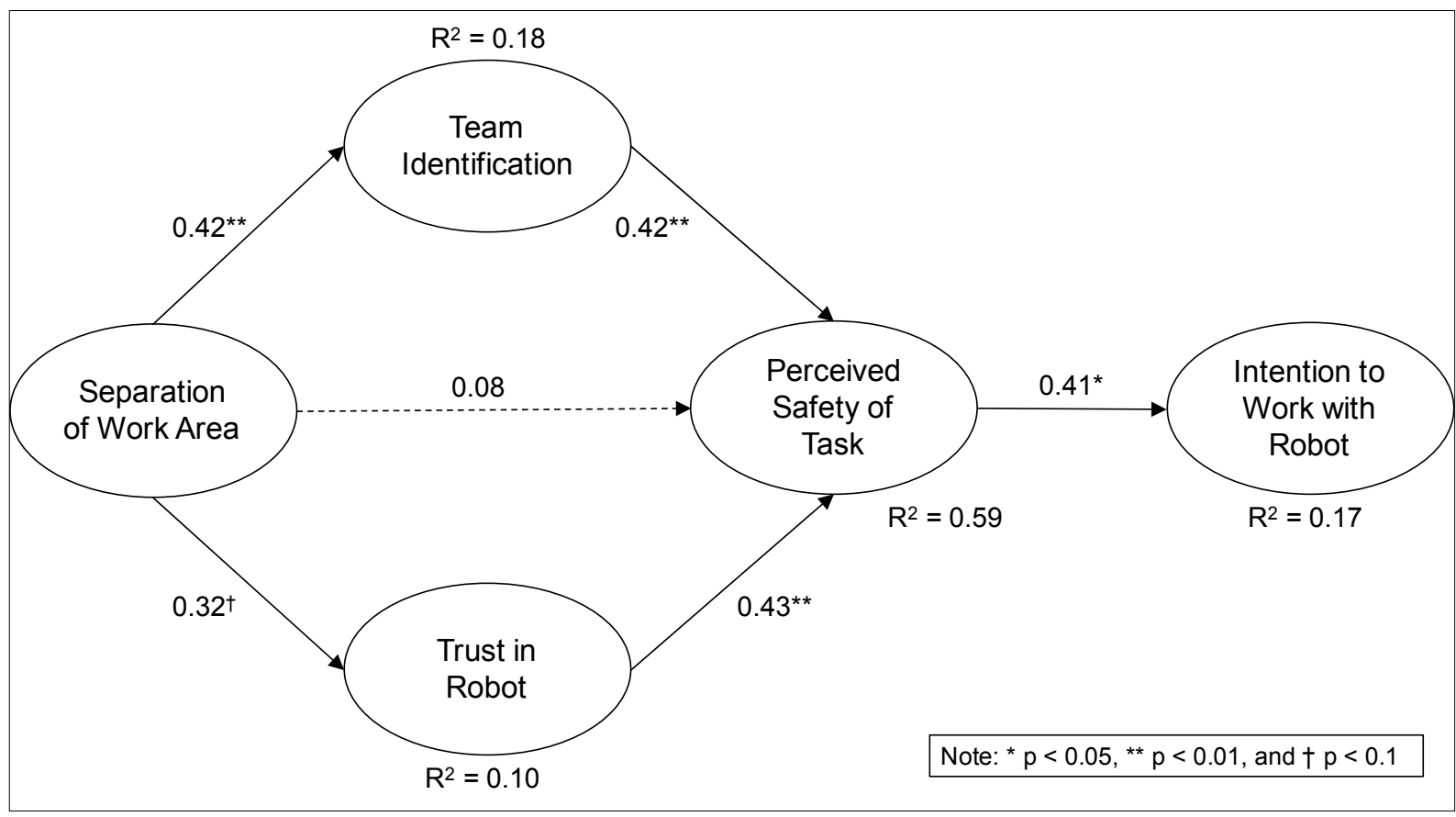

$\mathrm{H} 1$ posited that working in separate work areas would increase perceived safety of

the work with the robot. In order to test H1, a linear regression was conducted between

separation of work area and perceived safety of task separately, so the results are not shown in the full model in Figure 5. Results showed a strong main effect of separation of work area on perceived safety of task $\left(\beta=0.40, \mathrm{R}^{2}=0.16, p<0.01\right)$. H1 was supported.

$\mathrm{H} 2 \mathrm{a}$ and $\mathrm{H} 2 \mathrm{~b}$ stated that the impact of work area separation on perceived safety

would be mediated by team identification and trust in the robot. Conceptually, mediation means that the impact of $\mathrm{X}$ on $\mathrm{Y}$ occurs through another $\mathrm{M}$ variable. In the case of $\mathrm{H} 2 \mathrm{a}$ and $\mathrm{H} 2 \mathrm{~b}$, the impact of work separation on perceived safety occurred through increases in team identification and trust in the robot. In order to test the mediation effects, we employed Baron and Kenny's (1986) 
1 approach. This approach to testing mediation effects is conducted by comparing the direct

2 effect of the independent variable on the dependent variable between when the mediator

variables are included and when they are not included. For a mediation effect to exist, when

there is a significant direct effect of the independent variable, the effect of the mediator is

significant, and in this case the effect of the independent variable is reduced (Baron \& Kenny, 1986). Following the procedure, the results showed that both team identification and trust in the robot mediated the positive impact of separation of the work areas. In the model, all paths leading to perceived safety of the masonry task from separation of the work areas via the mediators were significant and reduced the direct effect of separation of the work areas on perceived safety of the masonry task (i.e. the direct effect of separation of work areas, as tested in H1, was no longer significant when team identification and trust in the robot were present). The mediation effects explained $59 \%$ of the variance of perceived safety of the masonry task. Another approach for testing for mediation effects is using SPSS Process Macro by A. F. Hayes (2013). We used the SPSS Process Macro to determine whether the indirect effects of work area separation on perceived safety through team identification and trust in the robot were statistically significant and whether the direct effect of work area separation was insignificant (A. F. Hayes, 2013). The results indicated that the impact of work area separation became insignificant $(\mathrm{B}=0.21, p<0.52)$ when there were significant indirect 
1 effects of team identification and trust in the robot. In Table 3, both indirect effects of team

2 identification and trust in robot are statistically significant by not including zero between

\begin{tabular}{|l|c|}
\hline \multicolumn{1}{|c|}{ Hypotheses } & Results \\
\hline H1) Separation of work area increases perceived safety of the task. & Supported \\
\hline $\begin{array}{l}\text { H2) Team identification and trust in the robot mediate the positive } \\
\text { impact of separation of the work area on perceived safety of the task. }\end{array}$ & Supported \\
\hline $\begin{array}{l}\text { H3) Perceived safety in the work area increases intention to work with } \\
\text { the robot. }\end{array}$ & Supported \\
\hline
\end{tabular}

\section{Discussion}

Table 3 Results of Mediation Analysis using SPSS Process Macro

\begin{tabular}{|c|c|c|c|c|c|}
\hline \multicolumn{6}{|c|}{ Indirect effects of Work Area Separation on Perceived Safety } \\
\hline & Coefficient & SE & LLCI & ULCI & Significance \\
\hline Total Effect & 0.68 & 0.33 & 0.12 & 1.37 & Yes \\
\hline Team Identification & 0.35 & 0.24 & 0.03 & 1.00 & Yes \\
\hline Trust in Robot & 0.33 & 0.26 & 0.01 & 1.08 & Yes \\
\hline \multicolumn{6}{|c|}{$\begin{array}{l}\text { Note: The analysis was done using SPSS Process Macro with } 5,000 \text { bootstrap samples. } \\
\text { Coefficients are unstandardized. } \\
\text { LLCI: Lower level confidence interval; ULCI Upper level confidence interval. } \\
\text { Statistically significant paths do NOT contain zero between lower and upper level confidence intervals. }\end{array}$} \\
\hline
\end{tabular}

Last, H3 posited the positive effect of perceived safety of the task on an individual's

intention to work with the robot. The model indicates that the path between the perceived

safety and intention to work with the robot is statistically significant $\left(\beta=0.41, \mathrm{R}^{2}=0.17, p<\right.$

0.05). Therefore, H3 is supported. Table 4 provides a summary of the hypotheses testing.

Table 4 Summary of Hypothesis Testing 
1 the context of construction work. We used an IVE in this experimental study to create two

2 virtual construction sites with varying degrees of work separation between an individual and a

3 robot. Our results show that separation of work areas between a human and the robot

$4 \quad$ increased the perceived safety associated with the task by promoting team identification and

5 trust in the robot. The results also demonstrated that greater perceived safety enhanced an

6 individual's intention to work with the robot again. Next, we discuss the contributions and

$7 \quad$ implications of the study.

\subsection{Theory on HRWC in Construction Work}

This study also contributes to the theory of HRWC in two ways. The first is by proposing and testing the RASM. Results of our study show that separating work areas is important for better understanding perception of safety in human-robot collaboration. This means that characteristics of a work environment can alter humans' subjective perception toward the robot and facilitate their intention to work with robots. Our finding implies that future research should examine other aspects of work environments to promote perception of safety associated with HRWC. For instance, scholars might investigate whether temporal separation of work between a human worker and robot, as a buffer for human-robot physical contact, also contributes to the safety perceptions in collaborative construction tasks. Our results also highlight that team identification and trust in the robot can account for the positive impact of work area separation. Team identification and trust have been 
1 understood as important psychological factors in teamwork to predict team outcomes (Robert

2 et al., 2008; Van Der Vegt \& Bunderson, 2005). It has been shown that these constructs play

3 significant roles in predicting outcomes of teams working with robots (de Visser \&

4 Parasuraman, 2011; Robert \& You, 2015). This study provides evidence that team

5 identification and trust associated with a robot are also important to promoting positive

6 perceptions and attitudes toward robots in construction tasks. Specifically, it will be critical

7 for collaborative construction teams using robots to ensure that workers establish a team

8 membership and trusting relationship with their robots (You \& Robert, 2018). Future research

9 is necessary in this area to identify other characteristics of work environments that promote

10 team identification and trust in robots in HRWC.

still may not feel safe. This gap between actual and perceived safety should not be ignored. and the RASM should prove to be particularly useful in this endeavor.

\subsection{Practical Implications}

Findings from this study provide several implications for practice in construction

work. First, work environments should be designed to enhance workers' safety perceptions. 
1 higher safety. For instance, installation of safety fences between the two work areas could be

2 effective for the separation without compromising visibility and monitoring of the robot's

3 behavior. On real construction sites, a robot's movement flow should not overlap with a

4 human worker's flow so that their work areas remain separate even in tasks that require

5 mobility.

Second, IVEs can be implemented as a training medium for human workers before

7 they work with a robot. In order to minimize injury and improve effectiveness of

8 collaboration, construction teams could build a simulated environment in an IVE to

9 familiarize employees with working with a virtual model of a robotic collaborator. In

10 designing robots, IVEs can also be used for prototyping of robots to be deployed to various

construction sites. Taken together, IVEs can allow construction teams to develop better robots

for construction tasks and design a safer work environment for human workers.

\subsection{IVEs for Construction Research} phenomena in construction tasks. In this study, we used an IVE to create a situation where an individual performed a realistic construction task — the masonry task — at a virtual construction site. By using widely available resources including a commercial game engine 
1 in which the work arrangement with a robot could easily be manipulated by 3-D modeling.

2 Based on literature that shows no difference between task performance and experience between a physical environment and benchmarked IVEs (Heydarian et al., 2015), we believe that results of our study can be transferred to real-world settings. Thus, this study is one of the first to showcase IVEs as a convenient and methodologically valid medium to test various human behaviors associated with construction tasks involving robots.

As robots are increasingly adopted at various construction tasks, the IVEs will become more useful for research of automation in construction. Properties of our IVEs can be extended to other contexts and types of construction collaboration. For instance, using the game engine, researchers could redesign the physical appearance of the robot or vary the intelligence of the robot or its behaviors. There is an established developer community for 3D models and behaviors that are pre-programmed, so researchers could easily build IVEs to represent various construction tasks and scenarios.

\subsection{Limitations}

This experiment has several limitations. The majority of participants were recruited from among undergraduate and graduate engineering students with a high education level and a lack of construction experience. It is possible that construction workers, who would be the actual end-users, might perceive HRWC differently from these students. Also, the study employed one type of construction task - masonry work between a single robot and a human 
1 worker. Future studies should test the RASM in other contexts, such as teams working with

2 robots involving multiple workers and robots and HRWC for excavation tasks. Furthermore,

3 some types of robots may not require separation. For instance, robotic exoskeleton renders

4 different qualities because it can be worn by construction workers, which may elicit different

5 perceptions on safety and trust in the robot. Lastly, it should be noted that the duration of the

6 interaction in the IVE was brief (7 minutes). The duration was determined to be short in order

7 to avoid participants' mental and physical discomfort such as motion sickness and weight of

8 the HMD. Future studies should employ more advanced equipment to create better IVEs with

9 more comfort and realistic duration of the interaction.

\section{Conclusion}

Despite the recent advances in robotic technology, it is still challenging to create a

safe work environment when robots and humans work together in a close proximity. Research has been exploring different ways to overcome the challenge and enhance safety perception in the human-robot collaborative work space. However, the high cost of employing robots to study human safety makes it difficult for scholars to conduct research in this topic. Also, the lack of theoretical framework prevents a systemic understanding of antecedents of perception of safety and its consequences across different settings of HRWC. In this paper, we proposed and tested the RASM to explain the impacts of separating humans and robots into two different work areas. To test the theoretical framework, we 
1 conducted an experiment in an immersive virtual environment. Participants were invited to a

2 lab to work with a 3D-rendered robot for a collaborative construction task using a HMD.

3 Results from our study generally confirm the benefits of IVEs. Participants reported that the

4 separation of work area increases perceived safety of the task and that this relationship is

5 mediated by team identification and trust toward the robot. In addition, we also found that

6 perceived safety in the work are increases intention to work with the robot. These results,

7 overall, empirically validate the RASM model. Thus, the results provide support for the need

8 to separate humans and robots by employing a safety fence. Immersive virtual environments

9 have the potential to provide a flexible, low-cost, and rapid approach to studying HRWC. The

10 adoption of IVEs as a research tool has the potential to help provide additional insights into

11 HRWC in the context of construction work.

\section{Acknowledgments}




\section{References}

Ajzen, I. (1985). From intentions to actions: A theory of planned behavior. J. Kuhl, \& J. Beckman (Eds.), Action-control: From cognition to behavior (pp. 11-39). Heidelberg: Springer. https://doi.org/10.1007/978-3-642-69746-3_2

Ajzen, I. (1991). The theory of planned behavior. Organizational Behavior and Human Decision Processes, 50(2), 179-211. https://doi.org/10.1016/0749-5978(91)90020-T

Arai, H., Takubo, T., Hayashibara, Y., \& Tanie, K. (2000). Human-robot cooperative manipulation using a virtual nonholonomic constraint. In Proceedings of the IEEE International Conference on Robotics and Automation (Vol. 4, pp. 4063-4069). IEEE. Retrieved from http://ieeexplore.ieee.org/abstract/document/845365/

Atkinson, D. J., \& Clark, M. H. (2014). Methodology for study of human-robot social interaction in dangerous situations. In Proceedings of the second international conference on Human-agent interaction (pp. 371376). ACM. Retrieved from http://dl.acm.org/citation.cfm?id=2658871

Baron, R. M., \& Kenny, D. A. (1986). The moderator-mediator variable distinction in social psychological research: Conceptual, strategic, and statistical considerations. Journal of Personality and Social Psychology, 51(6), 1173. http://psycnet.apa.org/buy/1987-13085-001

Bartneck, C., Kulić, D., Croft, E., \& Zoghbi, S. (2009). Measurement instruments for the anthropomorphism, animacy, likeability, perceived intelligence, and perceived safety of robots. International Journal of Social Robotics, 1(1), 71-81. https://doi.org/10.1007/s12369-008-0001-3

Bauer, A., Wollherr, D., \& Buss, M. (2008). Human-robot collaboration: a survey. International Journal of Humanoid Robotics, 5(01), 47-66. https://www.worldscientific.com/doi/abs/10.1142/S0219843608001303

Blascovich, J., Loomis, J., Beall, A. C., Swinth, K. R., Hoyt, C. L., \& Bailenson, J. N. (2002). Immersive virtual environment technology as a methodological tool for social psychology. Psychological Inquiry, 13(2), 103-124. https://doi.org/10.1207/S15327965PLI1302_01

Brown, R., Condor, S., Mathews, A., Wade, G., \& Williams, J. (1986). Explaining intergroup differentiation in an industrial organization. Journal of Occupational Psychology, 59(4), 273-286. https://doi.org/10.1111/j.2044-8325.1986.tb00230.x

Buchner, R., Wurhofer, D., Weiss, A., \& Tscheligi, M. (2013, October). Robots in Time: How User Experience in Human-Robot Interaction Changes over Time. In Proceedings of the 5th International Conference on Social Robotics. Volume 8239 (pp. 138-147). Springer-Verlag New York, Inc.. Retrieved from http://link.springer.com/chapter/10.1007/978-3-319-02675-6_14

Burgoon, J. K. (1978). A communication model of personal space violations: Explication and an initial test. Human Communication Research, 4(2), 129-142. https://doi.org/10.1111/j.1468-2958.1978.tb00603.x

Chen, T. L., King, C.-H., Thomaz, A. L., \& Kemp, C. C. (2011). Touched by a robot: An investigation of subjective responses to robot-initiated touch. In Proceedings of the 6th ACM/IEEE International Conference on Human-Robot Interaction (HRI), 2011 (pp. 457-464). IEEE. Retrieved from http://ieeexplore.ieee.org/abstract/document/6281380/

Chin, W. W. (1998). The partial least squares approach to structural equation modeling. Modern Methods for 
Business Research, 295(2), 295-336. ISBN: 0-8058-2677-7

de Visser, E., \& Parasuraman, R. (2011). Adaptive aiding of human-robot teaming effects of imperfect automation on performance, trust, and workload. Journal of Cognitive Engineering and Decision Making, 5(2), 209-231. http://journals.sagepub.com/doi/abs/10.1177/1555343411410160

Dosey, M. A., \& Meisels, M. (1969). Personal space and self-protection. Journal of Personality and Social Psychology, 11(2), 93. http://psycnet.apa.org/doi/10.1037/h0027040

Du, G., \& Zhang, P. (2014). Markerless human-robot interface for dual robot manipulators using Kinect sensor. Robotics and Computer-Integrated Manufacturing, 30(2), 150-159. https://doi.org/10.1016/j.rcim.2013.09.003

Feng, C., Xiao, Y., Willette, A., McGee, W., \& Kamat, V. R. (2015). Vision guided autonomous robotic assembly and as-built scanning on unstructured construction sites. Automation in Construction, 59, 128 138. https://doi.org/10.1016/j.autcon.2015.06.002

Fishbein, M. (1979). A theory of reasoned action: Some applications and implications. Nebraska Symposium on Motivation, 27, 65-116. Retrieved from http://psycnet.apa.org/psycinfo/1982-21121-001

Fornell, C., \& Larcker, D. (1981). Evaluating Structural Equation Models with Unobservable Variables and Measurement Error. Journal of Marketing Research, 18(1), 39-50. doi:10.2307/3151312

Garg, A., \& Kamat, V. R. (2013). Virtual prototyping for robotic fabrication of rebar cages in manufactured concrete construction. Journal of Architectural Engineering, 20(1), 06013002. https://doi.org/10.1061/(ASCE)AE.1943-5568.0000134

Goodrich, M. A., \& Schultz, A. C. (2007). Human-robot interaction: a survey. Foundations and Trends in Human-Computer Interaction, 1(3), 203-275. http://dx.doi.org/10.1561/1100000005

Groom, V., \& Nass, C. (2007). Can robots be teammates?: Benchmarks in human-robot teams. Interaction Studies, 8(3), 483-500. https://doi.org/10.1075/is.8.3.10gro

Groom, V., Srinivasan, V., Bethel, C. L., Murphy, R., Dole, L., \& Nass, C. (2011). Responses to robot social roles and social role framing. In Proceedings of the International Conference on Collaboration Technologies and Systems (pp. 194-203). IEEE. Retrieved from http://ieeexplore.ieee.org/xpls/abs_all.jsp?arnumber=5928687

Hair, J. F., Ringle, C. M., \& Sarstedt, M. (2011). PLS-SEM: Indeed a silver bullet. Journal of Marketing Theory and Practice, 19(2), 139-152. https://doi.org/10.2753/MTP1069-6679190202

Hall, E. T. (1966). The hidden dimension (1st ed.). New York, NY, US: Doubleday \& Co. Retrieved from http://psycnet.apa.org/psycinfo/2003-00029-000

Hayes, A. F. (2013). Introduction to mediation, moderation, and conditional process analysis: A regressionbased approach. Guilford Press. ISBN: 9781462534654. Retrieved from https://www.guilford.com/books/Introduction-to-Mediation-Moderation-and-Conditional-ProcessAnalysis/Andrew-Hayes/9781462534654

Hayes, B., \& Scassellati, B. (2013). Challenges in shared-environment human-robot collaboration. Learning, 8, 9. http://bradhayes.info/papers/hayes_challenges_HRI_collab_2013.pdf

Heydarian, A., Carneiro, J. P., Gerber, D., Becerik-Gerber, B., Hayes, T., \& Wood, W. (2015). Immersive virtual environments versus physical built environments: A benchmarking study for building design and user- 
built environment explorations. Automation in Construction, 54, 116-126.

https://doi.org/10.1016/j.autcon.2015.03.020

Ikeura, R., \& Inooka, H. (1995). Variable impedance control of a robot for cooperation with a human. In

Proceedings of the IEEE International Conference on Robotics and Automation (Vol. 3, pp. 3097-3102).

IEEE. Retrieved from http://ieeexplore.ieee.org/abstract/document/525725/

Inoue, K., Nonaka, S., Ujiie, Y., Takubo, T., \& Arai, T. (2005). Comparison of human psychology for real and virtual mobile manipulators. In Proceedings of the IEEE International Workshop on Robot and Human Interactive Communication (pp. 73-78). IEEE. Retrieved from http://ieeexplore.ieee.org/abstract/document/1513759/

Jermier, J. M., Gaines, J., \& McIntosh, N. J. (1989). Reactions to physically dangerous work: A conceptual and empirical analysis. Journal of Organizational Behavior, 10(1), 15-33. https://doi.org/10.1002/job.4030100103

Jian, J.-Y., Bisantz, A. M., \& Drury, C. G. (2000). Foundations for an empirically determined scale of trust in automated systems. International Journal of Cognitive Ergonomics, 4(1), 53-71. https://doi.org/10.1207/S15327566IJCE0401_04

Kamat, V. R., \& Martinez, J. C. (2005). Dynamic 3D visualization of articulated construction equipment. Journal of Computing in Civil Engineering, 19(4), 356-368. https://doi.org/10.1061/(ASCE)08873801(2005)19:4(356)

Kennedy, D. P., Gläscher, J., Tyszka, J. M., \& Adolphs, R. (2009). Personal space regulation by the human amygdala. Nature Neuroscience, 12(10), 1226-1227. https://doi.org/10.1038/nn.2381

Knight, W. (2014). Human-Robot Collaboration Will Alter Manufacturing. www.technologyreview.com. Retrieved June 7, 2015, from http://www.technologyreview.com/news/530696/how-human-robotteamwork-will-upend-manufacturing/

Kosuge, K., Yoshida, H., \& Fukuda, T. (1993). Dynamic control for robot-human collaboration. In Proceedings of the 2nd IEEE International Workshop on Robot and Human Communication (pp. 398-401). IEEE. Retrieved from http://ieeexplore.ieee.org/abstract/document/367685/

Kosuge, Kazuhiro, \& Kazamura, N. (1997). Control of a robot handling an object in cooperation with a human. In Proceedings of the 6th IEEE International Workshop on Robot and Human Communication (pp. $142-$ 147). IEEE. Retrieved from http://ieeexplore.ieee.org/abstract/document/646971/

Kulić, D., \& Croft, E. A. (2006). Real-time safety for human-robot interaction. Robotics and Autonomous Systems, 54(1), 1-12. https://doi.org/10.1016/j.robot.2005.10.005

Larsson, T. J., \& Field, B. (2002). The distribution of occupational injury risks in the Victorian construction industry. Safety Science, 40(5), 439-456. https://doi.org/10.1016/S0925-7535(01)00015-7

Lee, S. Y., Lee, K. Y., Lee, S. H., Kim, J. W., \& Han, C. S. (2007). Human-robot cooperation control for installing heavy construction materials. Autonomous Robots, 22(3), 305. https://doi.org/10.1007/s10514006-9722-z

Lieberz, K. A., Windmann, S., Geniole, S. N., McCormick, C. M., Mueller-Engelmann, M., Gruener, F., ... Steil, R. (2017). The facial width-to-height ratio determines interpersonal distance preferences in the observer. Aggressive Behavior. Retrieved from http://onlinelibrary.wiley.com/doi/10.1002/ab.21704/full 
Liker, J. K., \& Sindi, A. A. (1997). User acceptance of expert systems: a test of the theory of reasoned action. Journal of Engineering and Technology Management, 14(2), 147-173. https://doi.org/10.1016/S09234748(97)00008-8

Marcoulides, G. A., \& Saunders, C. (2006). Editor's comments: PLS: a silver bullet? MIS Quarterly, iii-ix. DOI: $10.2307 / 25148727$

Messner, J. I. (2006). Evaluating the use of immersive display media for construction planning. In Intelligent computing in engineering and architecture (pp. 484-491). Springer. Retrieved from http://link.springer.com/chapter/10.1007/11888598_43

Mumm, J., \& Mutlu, B. (2011). Human-robot proxemics: physical and psychological distancing in human-robot interaction. In Proceedings of the 6th international conference on Human-robot interaction (pp. 331-338). ACM. Retrieved from http://dl.acm.org/citation.cfm?id=1957786

Murphy, R. R. (2004). Human-robot interaction in rescue robotics. IEEE Transactions on Systems, Man, and Cybernetics, Part C: Applications and Reviews. 34(2), 138-153. https://doi.org/10.1109/TSMCC.2004.826267

Nahrgang, J. D., Morgeson, F. P., \& Hofmann, D. A. (2011). Safety at work: a meta-analytic investigation of the link between job demands, job resources, burnout, engagement, and safety outcomes. Journal of Applied Psychology, 96(1), 71. Retrieved from http://psycnet.apa.org/journals/apl/96/1/71/

Or, C. K., Duffy, V. G., \& Cheung, C. C. (2009). Perception of safe robot idle time in virtual reality and real industrial environments. International Journal of Industrial Ergonomics, 39(5), 807-812.

Park, J.-J., Kim, B.-S., Song, J.-B., \& Kim, H.-S. (2007). Safe link mechanism based on passive compliance for safe human-robot collision. In Proceedings of the IEEE International Conference on Robotics and Automation (pp. 1152-1157). IEEE. Retrieved from http://ieeexplore.ieee.org/abstract/document/4209244/

Reed, K. B., \& Peshkin, M. A. (2008). Physical collaboration of human-human and human-robot teams. IEEE Transactions on Haptics, 1(2), 108-120. https://doi.org/10.1016/j.ergon.2009.01.003

Ringle, C. M., Wende, S., \& Will, A. (2005). SmartPLS 2.0 (Beta). Hamburg. Germany. Available in http://www. smartpls. de.

Robert, L. P. (2013). Trust and Control in Virtual Teams: Unraveling the impact of Team Awareness Systems in Virtual Teams. In Workshop on Trust in Virtual Teams: Theory at the ACM Conference on Computer Supported Cooperative Work \& Social Computing. http://hdl.handle.net/2027.42/135720

Robert, L. P., Dennis, A. R., \& Ahuja, M. K. (2008). Social Capital and Knowledge Integration in Digitally Enabled Teams. Information Systems Research, 19(3), 314-334. https://doi.org/10.1287/isre.1080.0177

Robert, L. P., \& Sykes, T. A. (2016). Extending the Concept of Control Beliefs: Integrating the Role of Advice Networks. Information Systems Research, 28(1), 84-96. https://doi.org/10.1287/isre.2016.0666

Robert, L. P., \& You, S. (2015). Subgroup Formation in Teams Working with Robots. In Proceedings of the 33rd Annual ACM Conference Extended Abstracts on Human Factors in Computing Systems (pp. 20972102). ACM. Retrieved from http://dl.acm.org/citation.cfm?id=2732791

Salvini, P., Laschi, C., \& Dario, P. (2010). Design for acceptability: improving robots' coexistence in human society. International Journal of Social Robotics, 2(4), 451-460. https://doi.org/10.1007/s12369-0100079-2 
Sardar, A., Joosse, M., Weiss, A., \& Evers, V. (2012). Don't stand so close to me: users' attitudinal and behavioral responses to personal space invasion by robots. In Proceedings of the seventh annual ACM/IEEE international conference on Human-Robot Interaction (pp. 229-230). ACM. Retrieved from http://dl.acm.org/citation.cfm?id=2157769

Sauppé, A., \& Mutlu, B. (2014). How Social Cues Shape Task Coordination and Communication. In Proceedings of the 17th ACM Conference on Computer Supported Cooperative Work \& Social Computing (pp. 97-108). New York, NY, USA: ACM. https://doi.org/10.1145/2531602.2531610

Sawacha, E., Naoum, S., \& Fong, D. (1999). Factors affecting safety performance on construction sites. International Journal of Project Management, 17(5), 309-315. https://doi.org/10.1016/S02637863(98)00042-8

Schneider, S., \& Susi, P. (1994). Ergonomics and construction: a review of potential hazards in new construction. American Industrial Hygiene Association, 55(7), 635-649. https://doi.org/10.1080/15428119491018727

Sirkin, H. L., Zinser, M., \& Rose, J. (2015). Industries and Economies Leading the Robotics Revolution. www.bcgperspectives.com. Retrieved December 13, 2015, from https://www.bcgperspectives.com/content/articles/lean-manufacturing-innovation-industries-economiesleading-robotics-revolution/

Sommer, R. (1969). Personal Space: The Behavioral Basis of Design. Prentice Hall Direct. ISBN: 9780136575771. Retrieved from http://eric.ed.gov/?id=ED036112

Strube, M. J., \& Werner, C. (1984). Personal space claims as a function of interpersonal threat: The mediating role of need for control. Journal of Nonverbal Behavior, 8(3), 195-209. https://doi.org/10.1007/BF00987291

Takayama, L., \& Pantofaru, C. (2009). Influences on proxemic behaviors in human-robot interaction. In Proceedings of the. IEEE/RSJ International Conference on Intelligent Robots and Systems (pp. 54955502). IEEE. Retrieved from http://ieeexplore.ieee.org/xpls/abs_all.jsp?arnumber=5354145

Tan, J. T. C., Duan, F., Zhang, Y., Kato, R., \& Arai, T. (2009). Safety design and development of human-robot collaboration in cellular manufacturing. In Proceedings of the IEEE International Conference on Automation Science and Engineering (pp. 537-542). IEEE. Retrieved from http://ieeexplore.ieee.org/abstract/document/5234120/

Tharaldsen, J. E., Mearns, K. J., \& Knudsen, K. (2010). Perspectives on safety: The impact of group membership, work factors and trust on safety performance in UK and Norwegian drilling company employees. Safety Science, 48(8), 1062-1072. https://doi.org/10.1016/j.ssci.2009.06.003

Thomessen, T., Hashimoto, H., Osumi, H., Niitsuma, M., \& others. (2014). An approach to path planning and real-time redundancy control for human-robot collaboration. In Proceedings of the IEEE/ASME International Conference on Advanced Intelligent Mechatronics (pp. 1018-1023). IEEE. Retrieved from http://ieeexplore.ieee.org/abstract/document/6878214/

Törner, M., \& Pousette, A. (2009). Safety in construction-a comprehensive description of the characteristics of high safety standards in construction work, from the combined perspective of supervisors and experienced workers. Journal of Safety Research, 40(6), 399-409. https://doi.org/10.1016/j.jsr.2009.09.005 
Van Der Vegt, G. S., \& Bunderson, J. S. (2005). Learning and performance in multidisciplinary teams: The importance of collective team identification. Academy of Management Journal, 48(3), 532-547. https://doi.org/10.5465/amj.2005.17407918

Vasic, M., \& Billard, A. (2013). Safety issues in human-robot interactions. In Proceedings of the IEEE International Conference on Robotics and Automation (pp. 197-204). IEEE. Retrieved from http://ieeexplore.ieee.org/abstract/document/6630576/

Venkatesh, V., Morris, M. G., Davis, G. B., \& Davis, F. D. (2003). User acceptance of information technology: Toward a unified view. MIS Quarterly, 425-478. DOI: 10.2307/30036540

Vermeulen, M., \& Wisse, M. (2010). Intrinsically safe robot arm: Adjustable static balancing and low power actuation. International Journal of Social Robotics, 2(3), 275-288. https://doi.org/10.1007/s12369-0100048-9

Vick, A., Surdilovic, D., \& Kruger, J. (2013). Safe physical human-robot interaction with industrial dual-arm robots. In 9th Workshop on Robot Motion and Control, (pp. 264-269). IEEE. Retrieved from http://ieeexplore.ieee.org/abstract/document/6614619/

Vogel, C., Walter, C., \& Elkmann, N. (2013). A projection-based sensor system for safe physical human-robot collaboration. In Proceedings of the IEEE/RSJ International Conference on Intelligent Robots and Systems (pp. 5359-5364). IEEE. Retrieved from http://ieeexplore.ieee.org/abstract/document/6697132/

Vukobratović, M. K., \& Ekalo, Y. (1996). New approach to control of robotic manipulators interacting with dynamic environment. Robotica, 14(01), 31-39. https://doi.org/10.1017/S0263574700018919

Walters, M. L., Dautenhahn, K., Koay, K. L., Kaouri, C., Boekhorst, R., Nehaniv, C., ... \& Lee, D. (2005). Close encounters: spatial distances between people and a robot of mechanistic appearance. In Proceedings of the 5th IEEE-RAS International Conference on Humanoid Robots (pp. 450-455). IEEE. Retrieved from http://ieeexplore.ieee.org/xpls/abs_all.jsp?arnumber=1573608

Weistroffer, V., Paljic, A., Callebert, L., \& Fuchs, P. (2013). A methodology to assess the acceptability of human-robot collaboration using virtual reality. In Proceedings of the 19th ACM Symposium on Virtual Reality Software and Technology (pp. 39-48). ACM. Retrieved from http://dl.acm.org/citation.cfm?id=2503726

Whisker, V. (2003). Using Immersive Virtual Environments to Develop and Visualize Construction Schedules for Advanced Nuclear Power Plants. In International Congress on Advances in Nuclear Power Plants. Retrieved from http://www.academia.edu/download/43147979/Task2_ICAPP.pdf

Williams, M. (2007). Building genuine trust through interpersonal emotion management: A threat regulation model of trust and collaboration across boundaries. Academy of Management Review, 32(2), 595-621. https://doi.org/10.5465/amr.2007.24351867

Ximenes, B. H., Moreira, Í. M., \& Kelner, J. (2014). Extreme human-robot interfaces: Increasing trust and assurance around robots. In Proceedings of the 23rd IEEE International Symposium on Robot and Human Interactive Communication (pp. 1006-1011). IEEE. Retrieved from http://ieeexplore.ieee.org/abstract/document/6926384/

Yagoda, R. E., \& Gillan, D. J. (2012). You want me to trust a ROBOT? The development of a human-robot interaction trust scale. International Journal of Social Robotics, 4(3), 235-248. 
https://doi.org/10.1007/s12369-012-0144-0

You, S., \& Robert Jr, L. P. (2018). Emotional Attachment, Performance, and Viability in Teams Collaborating with Embodied Physical Action (EPA) Robots. Journal of the Association for Information Systems, 19(5), 377-407. https://doi: 10.17705/1jais.00496

You, S., \& Robert, L. P. (2017). Teaming Up with Robots: An IMOI (Inputs-Mediators-Outputs-Inputs) Framework of Human-Robot Teamwork. International Journal of Robotic Engineering, 2(003). http://vibgyorpublishers.org/content/international-journal-of-robotic-engineering/ijre-2-003.pdf

You, S., Ye, T., \& Robert, L. (2017). Team Potency and Ethnic Diversity in Embodied Physical Action (EPA) Robot-Supported Dyadic Teams. In Proceedings of the International Conference on Information Systems. Seoul, South Korea: AIS. http://aisel.aisnet.org/icis2017/HumanBehavior/Presentations/3/

Zou, P. X., \& Zhang, G. (2009). Comparative study on the perception of construction safety risks in China and Australia. Journal of Construction Engineering and Management, 135(7), 620-627. https://doi.org/10.1061/(ASCE)CO.1943-7862.0000019 